\title{
A STUDY OF FIRST YEAR TERTIARY STUDENTS' MATHEMATICAL KNOWLEDGE- CONCEPTUAL AND PROCEDURAL KNOWLEDGE, LOGICAL THINKING AND CREATIVITY
}

\author{
${ }^{1}$ Gurudeo Anand Tularam and ${ }^{2}$ Kees Hulsman \\ ${ }^{1}$ Department of Mathematics and Statistics, \\ ${ }^{2}$ Department of Ecology, \\ Science Environment Engineering and Technology [ENV], Griffith University, Brisbane, Australia
}

Received 2013-06-13, Revised 2013-07-31; Accepted 2013-07-31

\begin{abstract}
This study focuses on students in first year environmental science degree programs where traditionally mathematical emphasis has been much less than the strict science or math majors. The importance now placed in applied mathematics means that students need to gain more conceptual and quantitative knowledge in not only the environmental degree programs but also in most if not all non-mathematical majors. In this study, the authors attempt to gain insights into why students fail in mathematical courses where the mathematical requirements are not as demanding as other strict math degree programs. This is done by examining student conceptual thinking patterns and strategies as evident in student prepared scripts. A total of 133 students were requested to prepare a focus sheet to summarize their knowledge on topics learned but they were also told that the focus sheets could be used in exams for notes. This motivated their sheet preparation. The students prepared weekly summaries and later revised and summarized them for later use. Detailed examination of such sheets allowed researchers to study students' knowledge in terms procedural work, math skills, strategies and conceptual knowledge. A study of linear, quadratic and limit sections led to interesting insights not only regarding revision strategies, knowledge of content, but also conceptual and procedural knowledge base and higher order skills such as problem solving focus. Logical and creative competencies were assessed in terms of how and what student focused upon or linked to in order to facilitate application of knowledge. The results show average levels of procedural and conceptual competence but rather low levels in logical and creative competence in preparation of scripts. Almost 50\% lacked competency in procedural work while around 54\% lacked conceptual competency. Given the emphasis placed procedural skills by students, the levels were lower than expected. However, the lack of structure in their work and deeper levels of understanding of links between the topics learned was concerning. These findings have implications for the first year mathematics teaching teams at universities especially the non-specialist mathematical majors.
\end{abstract}

Keywords: Tertiary Mathematics, Learning Algebra, Conceptual, Procedural, Logic, Higher Order Thinking, First Year University Mathematics, Environmental Science, Mathematics Education

\section{INTRODUCTION}

Students still believe that to be successful in mathematics means that they can carry out procedures and use algorithms, formulae and mathematical rules (Kaldo, 2011; Tall, 2004; Tularam, 2013a; 2013b; 1997a; Tularam and Amri, 2011). Rules and procedures are important but often these are memorized rather than

Corresponding Author: Gurudeo Anand Tularam, Department of Mathematics and Statistics, Science Environment Engineering and Technology [ENV], Griffith University, Brisbane, Australia 
conceptually acquired with deep meanings attached-a connected structural knowledge base (Tularam and Amri, 2011). Anecdotal evidence suggests that many students are still motivated to do as little as possible to pass university exams. It is often easier to memorize mathematical rules and formulas without concerns about conceptual and more deeper and connected understanding but this is problematic later when students are expected to apply their knowledge to real life or abstract problems (Tularam, 1997b; 2013b). There is ample literature that shows that students lack logical flow in thinking or creativity (De Guzman et al., 1998; Tall, 2004). There is also much research that shows students seldom realize the underlying reasons why procedures work, even consider alternatives, equivalent methods or procedures that may be more appropriate for the situation at handthat is, they lack higher order and critical thinking skills (Rach and Heinze, 2011).

In the past, university communities were less concerned with students who failed for they would often leave after a semester of work but this is no longer the case. Students are now attending universities with widely varying mathematical backgrounds, all seeking higher education outcomes. Of great concern more generally is however, students are not undertaking quantitative courses and therefore much lower numbers of students are now completing basic mathematics and science courses and degrees. This situation has led mathematicians to question and research why students fail in mathematics, or even when successful, why they are often not interested in attempting higher level mathematic courses or degrees.

The teaching of mathematics in universities has received some attention in recent times particularly in terms of the higher order thinking requirements (De Guzman et al., 1998; Tall, 2004; Tularam and Amri, 2011; Tularam, 2013a; Kelson and Tularam, 1998a). Tall (2004) noted that while studying mathematics at an advanced level, students often experience an "abstraction shock", mainly due to the much more formal nature of mathematics presented at universities than that they have learned at high schools. Similarly, De Guzman et al. (1998) noted that "the mathematics is different not only because the topics are different, but more to the point because of an increased depth, both with respect to the technical abilities needed to manipulate the new objects and the conceptual understanding underlying them" (p. 752). It is not surprising then that many tertiary lecturers are finding it difficult to lecture, teach or facilitate mathematics to the first year university students.

The previously successful "lecture only method" has now become problematic and many lecturers may not be aware of how to improve the situation. It is clear that some have been rather slow to adapt and/or change while others are slowly coping with the changes needed to meet the goals of their so labelled modern students (Tularam, 2013a; 2013b; Tularam and Amri, 2011). As noted earlier, the nature of the students entering university has changed considerably over time (Griese et al., 2011). The students are no longer only the elite or higher achievers but more students with an average level of high school mathematics are entering universities with an aim to achieve higher education qualifications. This appears to be mainly due to the very low number of students choosing to do advanced mathematics in high school. However, university qualifications are well known to be correlated with higher incomes in the real world and thus many of the high schools students appear to progress to universities to gain specialist and higher qualifications.

One of the main challenges that Australia and indeed our tertiary institutions are currently facing is the lower numbers in science and mathematics degree programs. It is when science and mathematics have once again risen to become rather important with public arena also supporting the cause that ironically the numbers are trending down. Increasingly, mathematics is now being taught in many non-specialist math degree programs because the need for mathematical and quantitative skills have markedly increased in them. This has placed some strain in the retention of students in health, finance, business, planning, environmental and non-specialist math degree programs. The decline in numbers of students undertaking higher mathematics in Australia and New Zealand has led to the lowering of entry levels in many programs. This is not a Pacific problem only as the same trend have been significant in the US, UK and Germany among other countries all highlighting their concerns regarding declining numbers (Tularam and Amri, 2011). In Germany, Griese et al. (2011) noted large numbers of mathematics students leaving before even graduation.

One of the reasons often given by students is that mathematics is too abstract or not immediately useful in everyday life and this tends to be true to the students' worlds and interests. However, researchers have provided reasons for the difficulties students experience when learning mathematics. According to Piaget's, for cognitive growth and acquisition of abstract learning students need to be at the formal operations stage as defined by Piaget (1973). It may be a fact that the students entering universities may not have reached the level of abstraction necessary to cope fully with the demands and levels of understanding that are involved in tertiary mathematical 
courses (Rach and Heinze, 2011). Others have also focused on conceptual, procedural, skills based competencies of students and noted them to be low (Tall, 2004; Tularam, 2013a; 2013b).

In addition to conceptual analysis, the affective domain variables such as motivation, attitude, beliefs and self-efficacy (Bandura, 2006; Griese et al., 2011; Leder and Grootenboer, 2005; Lester et al., 1989; McLeod, 1992; Mcleod and Adams, 1989; Skaalvik and Skaalvik, 2009; Zimmerman et al., 1992) have also been studied to gain deeper insights into how students learn more abstract and higher order content knowledge. In what ways do such variables influence the difficulties students face when learning mathematical ideas are important questions posed and tacked by some researchers (Hoyles et al., 2001; Liston and O’Donoghue, 2008; 2010; McLeod, 1992). In their study regarding the preparedness of first year university students, Tularam and Amri (2011) noted that student selfpreparation for study, motivation and persistence tended to play key roles in learning, assessments and in problem solving but clearly more needs to done to comprehend how students cope with learning higher mathematical ideas and notions at the tertiary level.

The main aim of this study is to examine environmental science students' learning focus in terms of the conceptual, procedural and logical aspects of mathematics in the first year of university study. A critical examination of students' written work is conducted to help expose the nature of their knowledge base in mathematics soon after they arrive from high school. The categories identified in the literature are used to assess student work in terms of conceptual and procedural competencies. Higher order skills in terms of logical and creative competencies are also assessed based on the details presented regarding the links made across topics, logical flow of steps. The nature of presentation of the scripts and revision sheets are further assessed in terms or creativity of connections amongst topics and applications for example. The authors were able to gain insights regarding the nature of student knowledge by analysis of a set of sampled topics. Based on the results and findings important conclusions and implications are developed for the first year mathematics teaching teams in terms of the focus on conceptual, procedural, logical competencies and creativity.

\subsection{Background}

There are a number of studies that have analysed the cognitive and affective domains in mathematics learning and problem solving. The role of students' beliefs, attitudes and motivation in the learning and teaching of mathematics has been noted (Tularam, 2013a; 1997a; Kelson and Tularam, 1998b; Tularam and Amri, 2011) but the affective domain is not the subject of study presented in this study, even when it is considered equally important. Griese et al. (2011) used the term view of mathematics that was earlier defined by Schoenfeld (1985) to refer to the overall results of experiences in mathematics. Using this definition Griese et al. (2011) studied engineering students regarding students' view of mathematics-that is, the result of all the experiences the students have had over time while learning. The authors concluded that "mathematical competence is not only about knowledge and skills, but also about disposition to act in productive ways" (p. 85). It is important to consider that the dispositions refer not only to affective aspects but also to deeper abilities to problem solve, apply logical and creative thinking to address the problem at hand that are driven by well-structured knowledge base (Griese et al., 2011). Lester et al. (1989) also advocated the importance conceptual and procedural knowledge in the development of solution processes when problem solving. Using this view, this study focuses on the depth of student cognitive structures and mathematical knowledge base; that is how deep are student conceptual structures and procedural competence for learning and problem solving when students are in their first year study at universities.

A deeper conceptual knowledge of algebra and symbols is critical to learning mathematics and success in problem solving. Sfard (1991) notion that a mathematical concept and the naming of that concept "mutually constitute each other into being" (p.47), is an example of symbol use in mathematics as a part of mathematical activity "in which students come to participate" (Sfard, 2000). Thus, the active social and cultural contextual aspects are drawn forming an integral part of the learning process. Essentially, the author argued that student use symbols as a proxy for concepts or ideas but this does not take place in isolation, but rather is set within the social and cultural norms; such as in a lecture room or classroom. It is certain that the mathematical culture is a special culture with fixed rules regarding a student's mathematical conduct and the use of symbols; in most cases requiring solutions to be constructed as a response to questions posed.

Berger (2006) reported that student at the tertiary level, "adopts the symbol of an improper integral with an infinite limit, makes use of the operations in a templatedriven format, without understanding, initially"; that is, the student "is using the mathematical signs in 
mathematical activities" (incoherent as they are to an outsider) (p. 19). If highly motivated the student can over time the student develop a better understanding either by active reflection upon the learning or by working backwards through similar textbook examples. This is the so called socio-cultural effect frame that appears to facilitate the induction of the student into the "cultural symbolic system" of mathematics (Niss and Hojgaard, 2011).

In the past, mathematical competence has been difficult to define succinctly. At the most general level, competency in mathematics is characterized both in terms of content (what mathematics students should know) and process (how students should go about doing and understanding mathematics). It does involve a student having knowledge, understanding and practically performing procedures, using their mathematical knowledge. It also includes student opinions about mathematics and any mathematical activity they undertake in situations where mathematical knowledge can play a role. Therefore, a student will need to know factual and procedural knowledge in addition to a number of concrete skills, but these are not sufficient in themselves to account for mathematical competence. So it is possible to conclude that mathematical competency involves a well-informed readiness to act appropriately in situations involving a certain type of mathematical challenge. In the end, mathematical competency must also include communication, mathematizing, representation, devising strategies, using symbolic, formal and technical language and operations, as well as deductive and logical reasoning (Turner, 2010).

Jacobs (2006) identified a number of critical indicators of success in mathematics and these are briefly explored in Table 1. According to Jacobs (2006), the student's reality has to do with their textual production as an expression of mathematical thought in response to instructions given, problems solved or questions set. In this manner, student reality may be revealed in their written work and student responses to problems posed. Some of the competencies identified have been categorised in Table 1. Neubrand (2005) stated that: "Different didactical traditions and ways of teaching lead to different "inner structures" of mathematical achievement, made visible by different performance in the types of mathematical activities" (p. 82). This suggests that a particular student's mathematical achievement may be judged by his/her written or verbal performance; that is, insights could be gained if student performances are analysed in terms of what the student was instructed to do; and indeed what $\mathrm{s} /$ he has presented as a written and/or verbal response. Therefore, the level of competency may be judged by a detailed examination of the text, response and written work produced. The student work can be analysed in terms of whether it exhibits rote learning, real world relevance, application and/or deep and flexible understanding, creativity and higher order thinking (Table 2). Thus, student competency levels may be developed from analysis and based on this, students' inner knowledge may then be judged (Table 3).

The above framework has been adapted for this study to allow the authors to examine the first year students'competency levels not long after they enter university mathematical courses in the environmental sciences.

\subsection{Study Group}

This study included a sample of 133 students chosen from 150 students in all. The students who presented a focus sheet qualified for selection from the first year mathematics course. This group also included some students from other areas such as education, business and health sciences as an elective. There exists approximately $16 \%$ failure yearly with some $2-3 \%$ withdrawing before census date opting to undertake the course later in the program since the course is compulsory. The course does include some revision from the first year high school work, but applications and depth of the content is more complex and higher level respectively. The students who have done Math $\mathrm{B}$ in Queensland (with higher than B grade) or Math C may find some aspects of the course easier than those from other courses. But those who have gained lower levels in Math B may still struggle through the university course even when they may have passed Math B well. Many students have done Math A (a less advanced course with statistics and general level maths) at school with much less algebra find the university course difficult. There are some adult students who are back after a number of years out of school, but they may have completed a bridging or TAFE course. The mature students are usually more motivated and diligent with a focus to pass first year mathematics course, even when they find it difficult. For mature and the Math A type students, the work may be new especially the algebra and calculus sections but they all have at least 6 weeks of preparation before mid-semester exam. It is important to note that most students may have done some algebra earlier in high school but frequently, many state their dislike of mathematics more generally highlighting their inability to grasp the more abstract work. 
Table 1. Interpretation of various competencies

\begin{tabular}{ll}
\hline Indicator & Interpretation \\
\hline Procedural competence & $\begin{array}{l}\text { This refers to a direct interpretation as revealed by the in-depth analysis and as indicated on the } \\
\text { body of knowledge schema revealed in responses. } \\
\text { The indicating the participant has understood the conceptual basis of the problem. } \\
\text { Conceptual competence } \\
\text { Logic }\end{array}$ \\
$\begin{array}{l}\text { Irrespective of whether the answer was correct or not, the logic indicator refers to logically } \\
\text { executed steps in the response. } \\
\text { This was used when it was evident that the participant reflected. Evidence for this may be noted in } \\
\text { in the text. An example could be "scratching out" work. } \\
\text { This indicator referred to evidence in the text of forthright solutions, preparedness to follow } \\
\text { through, with little or no hesitancy. }\end{array}$ \\
$\begin{array}{l}\text { This indicator shows how the participants dealt with test items that they struggled with. } \\
\text { Irrespective of the correctness of the mathematics used to solve the problem, this indicator labels } \\
\text { behaviour in the text which shows that the participant ventured outside of the norm in dealing with } \\
\text { the problem. The norm would be that would be described as constructed response solutions. }\end{array}$ \\
\hline
\end{tabular}

Table 2. Nature of learning and application

- Evidence of rote skills

- Evidence of real world relevance

- Evidence of real world application

- Evidence of deep and flexible learning

Table 3. Overall competency scale

- Not competent

- Poor competence

- Competent

- Good competence

- Very good competence

\section{MATERIALS AND METHODS}

The first year environment science degree students were requested to prepare a focus sheet for their learning in applied mathematics course from the start of the semester. This sheet produced weekly was to be revised over time to allow the writing of all that students believed was critically important to the topic to show the kind of understanding needed to use the sheet notes when solving problems for example. To motivate the development of the sheet, the students were told that they could use the sheets as notes during their two major examinations (totalling $70 \%$ of assessment). The students were requested to revise and re-prepare sheets for use in examinations prior to exam dates but all earlier prepared sheets that represented their learning of the topics in the semester were kept and analysed. No other instructions were given and thus the students prepared their focus sheets according to their own styles, interests and motivations without other external directives. Over the semester, they were able to develop a rather detailed sheet of two sided A4 paper. From these detailed notes on topics taught, the authors were able to gain some interesting insights regarding student competencies in a number of topics taught in first year mathematics.
Using the framework from the existing literature on learning as well as through a process of discussion and reflection, the authors identified a number of aspects of the focus sheets that represented student competence levels. The aspects were categorised into procedural, conceptual, logical and creative competencies. In this study, 133 student's sheets were examined in detail but rather than reviewing all content taught a sample of three topics were chosen: namely, linear, quadratics and limit sections of the course. These represented a set of topics often taught in first year mathematics courses and indeed aspects of which the students may have learned before undertaking the course at university.

In addition to the conceptual and procedural competencies mentioned in the literature, the quality of the work presented in the focus sheets was also evaluated in terms of logical development and creativity. Any evidence of logical steps and connections made in the steps were identified; and considered evidence of the same. Evidence of ways in which the content on the sheet was organised and/or linked with regards to topics and relations made between was judged as creativity in organisation and development of the focus sheets. This higher level abstracted view of the sheets led to inferences regarding deeper understanding of content and procedures and the use of higher order skills. While the main focus was the assessment of procedural, conceptual and logical competencies, student creativity in planning and organising the sheet was considered important; student knowledge and application in terms of the structure wasalso studied in depth based on the definitions in this study (Table 4); ore specifically, by identifying the number of connections and/or transfer of knowledge within steps in a topic area or across topics, links made regarding skills, procedure and content; and real life applications mentioned or shown. 
Table 4. Criteria for classifying students' mathematicalcompetencies

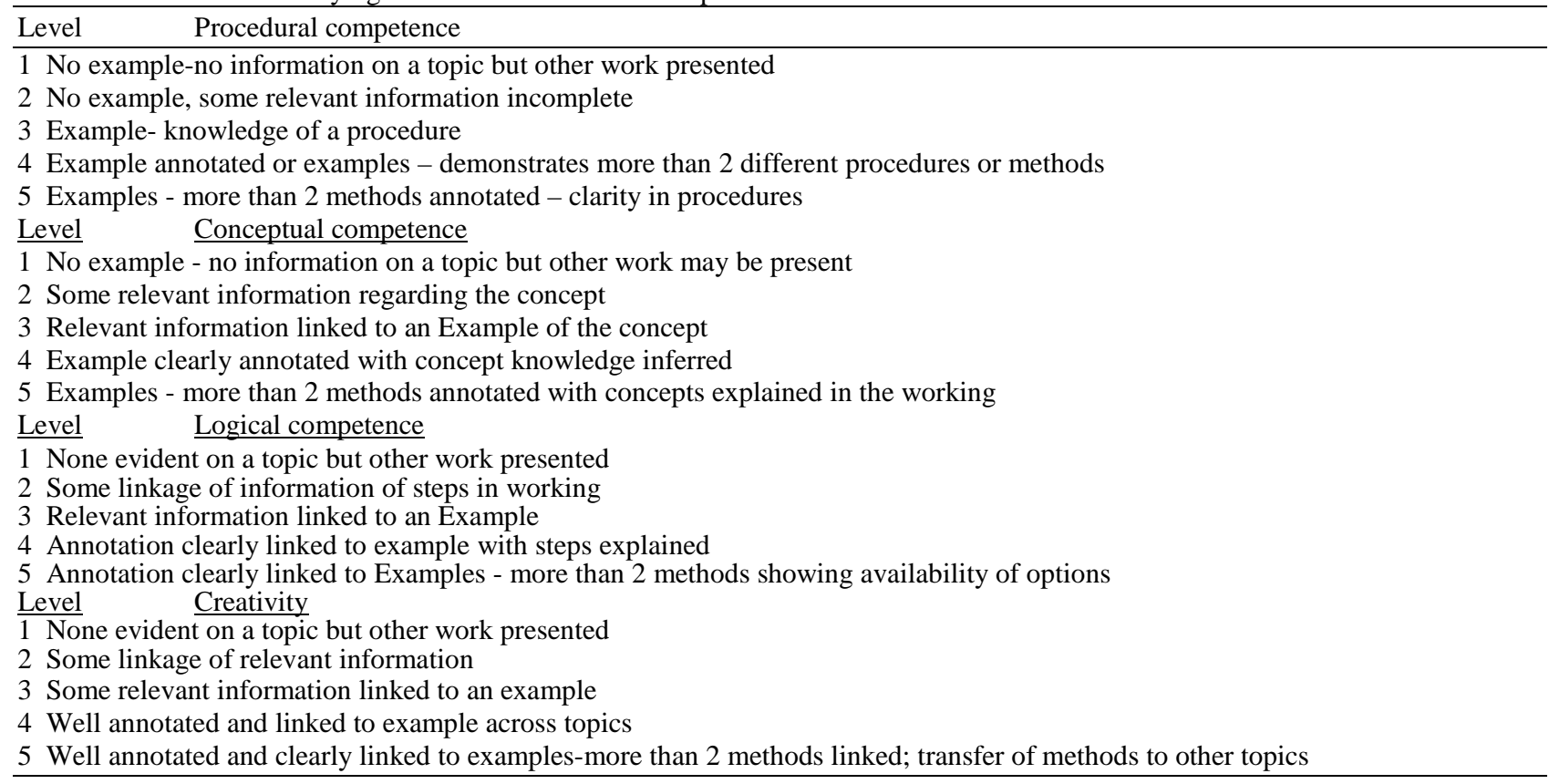

As noted earlier, the categories used in this study were developed based on frameworks already in the literature on competencies in mathematics learning. Analysis and refinement of such frameworks led to precise definitions and these in turn led to critical indictors for competency levels. The indicators further suggested the type of evidence and work required for level achieved. The logical and creative competencies identified are in line with the literature on deeper understanding of mathematics (Table 4). In the end, a numerical based criterion was developed to evaluate student performance in terms of competence level achieved (Table 4). Examples of how the criteria were applied to student work are shown with examples in boxes based on topics: Box 1 on linear equations and Box 2 (not included) on quadratic equations. Some typed examples of actual student work on linear, quadratic and limits as well as scoring in each are presented in appropriate sections.

The working definitions of competencies used to analyse the student focus sheets are: procedural competence, conceptual competence, logical competence and creativity:

- Procedural competence refers to the ability of the student to show the steps taken to solve a problem. There is clear evidence of a step by step method that is deemed appropriate for the solving a problem situation

- Conceptual competence refers to the depth of knowledge of a topic evident in student work with relationships among key ideas well understood; the student has shown or demonstrated a good understanding of the general idea within a topic and content relationships among the specific subtopics within a content area

- Logical competence refers to the way in which the information regarding content and topics in the preparation sheet were linked or related to each other; also whether the steps in sheets were logical in the order of presentation in terms of deductions made

- Creativity refers to the novels ways in which a sheet was developed; alternate ways in which the student presented the relevant information such as specifically showing the connections between the ways of considering a problem; relating the conceptual understanding to the relevant steps in a worked applied example as well as using applied examples, situations, or using in addition to logical steps, graphs to illustrate the relationships developed

A number based set of criteria for classifying student work in terms of mathematical competencies in specific areas identified is presented in Table 4.

\subsection{Examples of Competency in Linear}

As noted in the Table 4, procedural competence with linear equations was scored as 1 for nothing presented but 2 for a partially worked example, or a complete trivial example: e.g., calculation of the product of two 
slopes showing their product was "-1" for perpendicular lines; and 3 for completely worked example, e.g., $y-3=$ $4(x-0), y-3=4 x, y=4 x+3 ; 4$ for two or more worked examples each using a different method of solution, e.g. the linear equation using two points by determining the slope first; a mark of 4 was given as per a score of 3 but also solving different types of linear problems such as an inequality $|2 x-3|=5$ : showing the case of $2 x-3=5, x=4$ or $2 \mathrm{x}-3=-5 ; \mathrm{x}=-1$; and finally a mark of 5 was given for at least two completely worked examples annotated with the procedural steps (Box 1).

Conceptual competence was scored with one for nothing identified, while a mark of 2 was given for concepts presented but not clearly linked to one another, e.g., $\mathrm{m}=$ rise/run $=\Delta \mathrm{y} / \Delta \mathrm{x}$ not clearly linked to $\left(\mathrm{y}_{2^{-}}\right.$ $\left.\mathrm{y}_{1}\right) /\left(\mathrm{x}_{2}-\mathrm{x}_{1}\right)$, or to the equation $\mathrm{y}=\mathrm{mx}+\mathrm{b}$; or to the point slope equation $\mathrm{y}-\mathrm{y}_{1}=\mathrm{m}\left(\mathrm{x}-\mathrm{x}_{1}\right)$; a mark of 3 was given for some concepts clearly linked to one another via an example, such as $\mathrm{y}=\mathrm{mx}+\mathrm{b}$ where $\mathrm{m}=$ slope and $\mathrm{b}=\mathrm{y}$ intercept; to find $\mathrm{m} ; \Delta \mathrm{y} / \Delta \mathrm{x}=\left(\mathrm{y}_{2}-\mathrm{y}_{1}\right) /\left(\mathrm{x}_{2}-\mathrm{x}_{1}\right)$; a mark of 4 was given for concepts that were clearly linked to one another as for a score of 3 but additionally describing a process linking the relevant information to find the equation of a straight line passing through two points; and a mark of 5 was given for concepts that were clearly linked to relevant examples.

Logic was scored as 1 for nothing evident; 2 for some evidence of deduction or logic; reasoning in presentation of steps in written work; 3 for evidence of logical steps in the worked examples, e.g. $y=m x+b$ where $m=$ slope and $\mathrm{b}$ is the $\mathrm{y}$ intercept and how it can be obtained from $\mathrm{ax}+\mathrm{by}+\mathrm{c}=0$; or from the point slope $\mathrm{y}-\mathrm{y}_{1}=\mathrm{m}(\mathrm{x}-$ $\mathrm{x}_{1}$ ) equation; also in graphing by finding $\mathrm{x}$ and $\mathrm{y}$ axis cuts; (i) set $\mathrm{x}=0, \mathrm{y}=2$ presented in a logical manner; (ii) let $y=0, x=3$; and the use of logical reasoning when the slope value is used to plot for a second point on the graph; a mark of 4 as for three but for some of the steps of the process being made explicit in relation to a worked example; 5 as for 4 but for clear linkage of the steps in the process to worked examples with logical reasoning evident in the steps of the working or writing.

Creativity was scored as 1 for nothing evident; a mark of 2 for some spatial connection between conceptual information and worked examples; a mark of 3 for much more clarity in spatial connection between conceptual information and relationship to the worked example; a mark of 4 as for 3 but with other linking of graphs to the worked examples and across topics; and a mark of 5 as for 4 but with clarity in links with the conceptual information, graphs, worked examples and across topics with application examples included.

\subsection{Examples of Competency in Quadratic}

Procedural competence with quadratic equations was scored as 2 for a partially worked example; a mark of 3 was given for using a specific method to solve a quadratic equation, e.g. example 1, 2 or 3 in Box 2 (not included); a mark of 4 was given for using two different methods to solve quadratic equations, e.g., example 1 and 2 in Box 2; a mark of 5 was given for using three different methods for solving quadratic equations.

Conceptual competence with quadratic equations was scored as 2 for some conceptual information such as the general form of a quadratic equation $a x^{2}+b x+c=0$, perfect squares and difference of the squares; a mark of 3 for stating the general form of the quadratic equation and clear links to the terms in the quadratic formula and/or linking the perfect square and difference of the squares to solutions by factorising; a mark of 4 for the general form of the quadratic equation linked to the quadratic formula as well as some of the steps of the procedure annotated and a mark of 5 was given for in addition to the previous category all of the major steps of the process clearly annotated with application examples given and hidden quadratic outlined.

In summary, the procedural competence regarding the quadratic equations was scored as:

- For nothing presented

- For a partially worked example

- for using a specific method to solve a quadratic equation

- For using two different methods to solve quadratic equations

- For using three different methods for solving quadratic equations

The conceptual competence regarding the quadratic equations was:

- For nothing presented

- For some conceptual information such as the general form of a quadratic equation

- For stating the general form of the quadratic equation and clear links to the terms in the quadratic formula;

- For the general form of the quadratic equation linked to the quadratic formula as well as some of the steps of the procedure annotated; and

- As for the previous category but with all of the major steps of the process clearly annotated

The logical competence was judged in the same manner as in the linear section and based on the 
definition presented in the Table 4. Some students annotated examples and demonstrated reasoning behind the steps taken, e.g., in completing the squares with steps clearly specified as to what was done. This was considered to be based on logical reasoning; with creativity also judged in the process of the work but particular focus on the explicit demonstration of the linkages between process steps and their execution or considering alternative options of presentation. Average levels of logical and creative competencies were attributed to students who simply listed the steps in the process but did not relate them to each other;or those who even listed the steps and then presented a worked example but links could not be clearly inferred from the work. In some sequences, it may be inferred that the student followed the logic of the topic within steps when each line of the example did follow the correct sequence of written steps.

\subsection{Examples of Competency in Limits}

Conceptual competence was evident where students left and audit trail as they simplified expressions; for example, where they factorised the expression showing the same terms being cancelled; namely, the term ( $x-3)$ in the following limit problem:

$$
\lim _{x \rightarrow 3} \frac{x^{2}-3^{2}}{x-3}=\lim _{x \rightarrow 3} \frac{(x+3)(x-3)}{x-3}=\lim _{x \rightarrow 3} x+3=6
$$

It is also clear from the example above that the student would have used the expansion: $x^{2}-a^{2}=(x-a)(x$ $+\mathrm{a})$, then cancelled the common factors to simplify the expression so that the limit can be determined by substituting a as the value of $x$. Thus in general:

$$
\lim _{x \rightarrow a} \frac{x^{2}-a^{2}}{x-a}=\lim _{x \rightarrow a} \frac{(x+a)(x-a)}{x-a}=\lim _{x \rightarrow a} x+a=2 a
$$

In an example of the type below it is clear that the student understood the rule that 3 cannot be substituted for $x$ because the denominator would become 0 and the fraction meaningless; it is not possible to divide by 0 as the division is undefined:

$$
\lim _{x \rightarrow 3} \frac{x^{2}-x-6}{x-3}=6
$$

Therefore, it was necessary to factorise the numerator to obtain factors that may cancel with the expression in the denominator. If it is noted that $x-3$ and $x+2$ are the factors of the numerator expression, then student can cancel common factors; after which it is possible to substitute 3 for $\mathrm{x}$ to calculate the limit as shown below:

$$
\lim _{x \rightarrow 3} \frac{(x-3)(x+2)}{x-3}=5
$$

Even if a student did not state their conceptual knowledge explicitly, their level of conceptual knowledge can be inferred from the audit trail left in the working of examples. This would not be the case if the example used was copied directly from the text or lecture notes as that does not require conceptual competence, other than the student can recognise a relevant example.

Students who showed strong procedural competence demonstrated that they could use 2 or more different methods to solve a problem. For example: limits problems could be solved by substitution, factorisation, or dividing by the highest power in the denominator whichever is appropriate; high in procedural meant that the students showed at least 2 of these methods. The logical and creative competencies were judged in the same manner as stated for topics earlier and based on Table 4. However for a mark of 5 students would have to link the limits to hyperbola graphing and asymptotes; or demonstrate understanding of approaching values of functions; say when $x$ tends to a, y tend to $b$.

After conducting the above detailed analysis, it was then appropriate to categorise students into competent and not competent levels. Each level gained in a category can also represent a mark for the student in that category. That is, this mark may be used to represent the level achieved in a particular competency and used for higher level analysis. For the level of competency gained across all of the four categories in each of the topics (linear, quadratic and limit type problems), another grouping was considered: satisfactory or better competence (C) and unsatisfactory or low (LC) level of competence. The condition used for achieving a $\mathrm{C}$ was a mark of 3 or above in a category, while for LC was a mark less than or equal to 2 on a scale of 1 to 5 . In this way, overall numbers and percentages were developed for students categorised as either a C or an LC.

Any analysis of a qualitative nature may be subject to questions about judgements made in analysis regarding marking and categorisation of students' work. For this reason a short section on questionability and subjectiveness-limitations of the study is presented following the conclusion. 


\section{RESULTS AND DISCUSSION}

\subsection{Analysis of Competencies Gained Across Topics}

There was a possible score of 15 for each student in the competency level analysis. Figure 1 shows the students in general showed low levels of basic mathematical competencies as defined and judged by researchers. The logical and creative competencies were found to be rather lower than the former competencies. In linear functions, the students were taught straight line, graphing, linear expressions and equations, rearrangements of linear forms, inverses, absolute value functions, solving of linear and absolute value equations including applications of the linear models and so on. In most cases, the students sampled did not demonstrate procedural competence in linear topics stated above and their achievement would be hardly labelled as a satisfactory competence at the university level. Overall about $60 \%$ of the students performed at the competent level but the significant minority around $40 \%$ failed demonstrated effective procedural capability based on an in depth analysis their own notes. While a lot of linear work is rule based, there are many different rules that related to different sorts of linear equations such as inequality, absolute value and inverse of linear functions. Therefore the students had to be logical and creative in their approach. In the main, the solving of absolute value equation appeared to be a problem area but many did not actually note the significance of it in their written work either. The solving of absolute value problems does not rely solely on a set formula or fixed rules but rather students need to think logically through the problem to solve for $x$ by considering the meaning of the absolute value symbol and the linear term inside the symbol. Not surprisingly, rather few were judged to be logical and/or creative.

Although the students appeared to have an understanding of linear functions of the form $y=m x+c$ type,on the average the overall conceptual score on linear section was rather low in that only 59\% demonstrated linear competence and $41 \%$, which is a significant minority did not. Most students were not so proficient with inequalities, absolute value concept and inverses of linear functions. While the procedural competence was lower (46\%) in quadratics, in contrast to the linear section, a formula was available for equation solving in quadratics and it was noted that students could write the formula and work with it initially at least. This appeared to help raise their conceptual development in some manner as well in that the students demonstrated more "rounded" conceptual base with about $63 \%$ demonstrating conceptual competence in quadratics. That is, the students were more easily able to explain with evidence and examples, their knowledge of other methods of solving such as factorising; but to a lesser extent, completing the square.

In comparison to linear and the topics related to it, the students appeared to be more in tune with quadratic functions and mostly with the quadratic formula for solving equations. Also, comparatively higher logical and creative competencies were noted in the quadratics work of students when compared to linear (Table 11). Either the students did not need to write all they knew about linear topics or the students were more formula focused realizing that using the formula meant they could at least correctly solve equations for marks in exams; and this may have provided the impetus of more focus on it perhaps. A lot of students wrote the formula, but many did not link or annotate the coefficients in the formula. This may be due to the fact that they realised the relevance of each of the coefficients and the formula. However, the results in exams showed incorrect use of the formula particularly when the coefficients were negative; the students used positive values for negative coefficients. Also, often the division by $2 a$ in the denominator of the formula was applied incorrectly to only a part of the formula. This suggests that a formula driven learning is not enough for successful performance though it seems that this focus may somewhat improve conceptual competency.

In the limits section, the student were also lacking in procedural $(49 \%)$ and conceptual $(41 \%)$ competencies although the limit section was higher in logical competency $(40 \%)$ when compared to linear (13\%); but somewhat similar to logical in quadratic $(43 \%)$. In creativity, the level in the limit section (5\%) was similar to that in linear $(4 \%)$ but lower than that in quadratics $(20 \%)$. Once again the overall logical and creative competencies were rather low (Table 11). This is not as surprising since most students find limits and calculus concepts difficult to deal with. However, some basic rules were available in limits that students could provide all be it with low levels of conceptual and procedural competencies while working on them; this process also allowed students to demonstrate some logical and creative thinking patterns but the results were indeed low. It was noted that students lacked a deeper level understanding of limits; it was not often that students 
realised the approaching a number or asymptotic aspects of limits. The limit section was not related to graphing of hyperbola for example, where the concept of limits was first considered in the course to help students ease into the section on limits as well as to develop the concept of approach to a number, a value or an asymptotic schema.

Figure 1 shows that the overall distributions of each of the competencies analysed (max 15 marks). The conceptual scores appear to be more normally distributed when compared with others. The modal score of conceptual is 8/15 (approx. 53\%). The mode and the somewhat lower mean value of conceptual (7/15, approx. $46 \%)$ are surprising given that most of the students have completed a number of secondary school mathematics courses with some work being more or less revision.

Procedural competence-overall
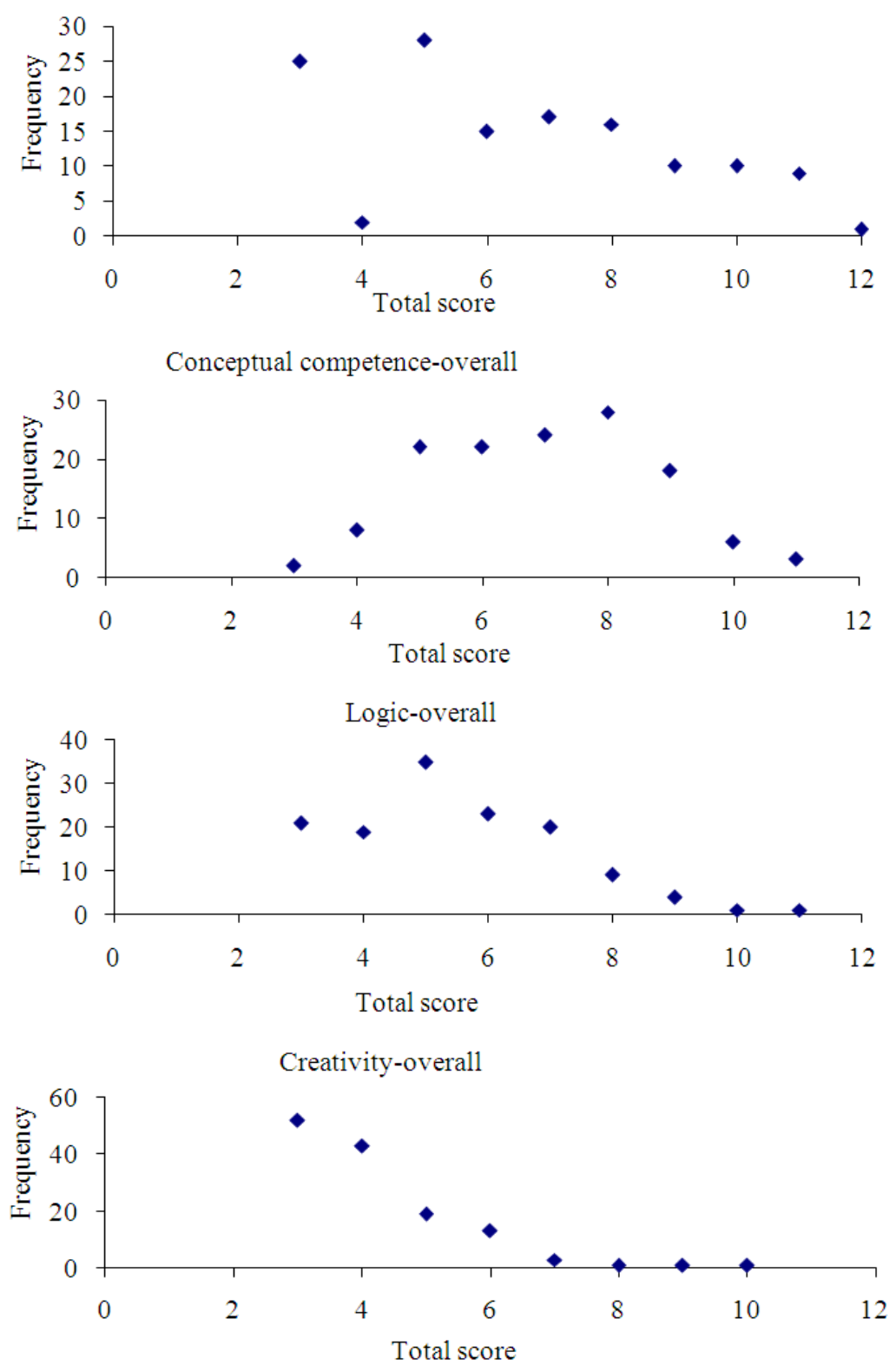

Fig. 1. Distribution of competencies-procedural, conceptual, logic and creativity 
However, mathematical learning is often disliked by the students entering the environmental science degree programs and as such their persistence and motivation levels during earlier learning at high school may have been wanting. There may be other reasons as well but some anecdotal and research evidence suggest that one of the key reasons is the lack of preparedness of students; that is they lack the self discipine to motivate themselves for higher level learning (Tularam and Amri, 2011; Tularam, 2013a; 2013b). It could also be that student motivation and interest wane due to the more abstract nature of mathematics. Even when the students had more than enough time to revise old work and indeed learn new mathematics till the examination (6 weeks), the results were low in both procedural competence and conceptual understanding. The distribution of the procedural competency appears similar to the logical distribution (Fig. 1). The mean score of the procedural competency is $6.5 / 15(43 \%)$ while the modal value is $5 / 15$ (approx. 33.3\%); the respective values for the logical competency is $5.4 / 15(36 \%)$ and $5 / 15(33.3 \%)$. The similarity seems to be related to the nature of judgements made in these two competencies. The student procedures were assessed on the written work and the written work also formed a basis for assessing logical ability-such as conditional and deductive reasoning, or even creativity, though to a much lesser extent. The logical judgment was based on the nature of the procedural presentation in the step by step manner as well as within an overall presentation. Indeed, student written work often shows evidence of not only the procedural work but also the logical nature of their thinking during the development of procedures.

It is not surprising then that there is some correlation between these two categories. However, the rather low number of students who achieved higher total scores in procedural competency (Fig. 1) is concerning when this is an area in which our students (teachers) place most emphasis when learning - the focus on procedural learning is in accord with the literature. Therefore the lower numbers of students in the higher scores in both procedural and conceptual distributions is somewhat surprising.

In contrast, students generally do not score well in higher order thinking skills according to the literature and this was confirmed in this study. The logical and creative competencies appeared significantly lower in overall scores. It is noted that students find logical thinking in a mathematics problem solving framework difficult to learn. Figure 1 shows there were rather low numbers in higher scores in both logical and creative thinking. The information presented in student work lacked connections and there was little evidence of links generated across topics. Also, few chose to relate their learned knowledge to application examples to help facilitate transfer of their learning either to theoretical or application examples or within and across topics.

The lower modal, median and mean values in each competency is somewhat surprising but the results appears to show that students reach formal operations at different stages but most of these students have yet to reach that formal stage-a la Piaget. Piaget (1960) formal operations stage notions may suggest that even when over the age of 16 or 17 students may only just be starting to develop abilities to understand more deeply the many abstract notions identified in mathematics. The low numbers of students undertaking mathematically based courses in high schools and universities further supports this view.

\subsection{Analysis of Content Knowledge-Linear, Quadratic and Limit}

Table 5 shows around 44\% (58/133) of students did not present an example or stated any of the methods that could be used to solve linear functions. About $33 \%$ (44/133) presented a rule with no examples and about $11 \%(14 / 133)$ did not present anything of the linear topic. Of the 133 students only $56 \%$ presented at least one example; around $28 \%$ presented only one example, $20 \%$ demonstrated two examples, about $7 \%$ presented three examples and $2 \%$ showed 4 examples. About $8 \%(12 / 133)$ used substitution, $13.5 \%$ (18/133) used the formula for the equation of line, while around $8 \%(10 / 133)$ included an inequality example in the topic of linear functions. Approximately 35\% (46/133) included absolute function and solving of such equations and around 34\% (45/133) considered the inverse of linear functions.

More specifically, about 28\% (37/133) of the students used one method to solve linear functions, while around $31 \%$ (41/133) demonstrated two or more methods to solve linear functions. Overall around 59\% (78/133) of the students demonstrated procedural competence in thelinear section; this was higher (as expected) when compared to quadratic (46\%: 61/133) and limit (49\%: 65/133) sections as noted earlier (Table 11).

The analysis showed that most students did not present an example of any of the methods that could be used to solve linear equations. This may be because they may have thought the work was simpler but some evidence in exams does not support this as many incorrect applications of linear work have been noted. Some topics taught in the linear section were not related to linear and this suggests that students were not able to relate the linear subtopics to each other based on similarity of solution processes and graphing for example; it seems that students failed to decipher higher order patterns that ought to be apparent in the section. For example, there were only a few who delved into the absolute value equations that are taught under the topic of linear but are more demanding to solve in that they require logical reasoning and thinking of possibilities. 
Table 5. Linear section-equation, inequality, absolute value and inverse

\begin{tabular}{|c|c|c|c|c|c|}
\hline Substitution & Equation & Inequality & Absolute & Inverse & Frequency \\
\hline$\sqrt{x}$ & $\mathrm{x}$ & $\mathrm{x}$ & $\mathrm{x}$ & 2 & \\
\hline$x \sqrt{ }$ & $\mathrm{x}$ & $\mathrm{x}$ & $\mathrm{x}$ & 7 & \\
\hline $\mathrm{x} \mathrm{x}$ & $\sqrt{ }$ & $\mathrm{x}$ & $\mathrm{x}$ & 1 & \\
\hline $\mathrm{XX}$ & $\mathrm{x}$ & $\sqrt{ }$ & $\mathrm{x}$ & 15 & \\
\hline $\mathrm{x} x$ & $\mathrm{x}$ & $\mathrm{x}$ & $\sqrt{ }$ & 12 & \\
\hline$\sqrt{x}$ & $\mathrm{x}$ & $\sqrt{ }$ & $\mathrm{x}$ & 2 & \\
\hline$\sqrt{x}$ & $\mathrm{x}$ & $\mathrm{x}$ & $\sqrt{ }$ & 3 & \\
\hline$x \sqrt{ }$ & $\mathrm{x}$ & $\sqrt{ }$ & $\mathrm{x}$ & 3 & \\
\hline$x \sqrt{ }$ & $\mathrm{x}$ & $\mathrm{x}$ & $\sqrt{ }$ & 3 & \\
\hline $\mathrm{xx}$ & $\sqrt{ }$ & $\mathrm{x}$ & $\sqrt{ }$ & 2 & \\
\hline $\mathrm{x} x$ & $\mathrm{x}$ & $\sqrt{ }$ & $\sqrt{ }$ & 13 & \\
\hline$\sqrt{ } \sqrt{ }$ & $\mathrm{x}$ & $\mathrm{x}$ & $\sqrt{ }$ & 1 & \\
\hline$\sqrt{x}$ & $\sqrt{ }$ & $\sqrt{ }$ & $\mathrm{x}$ & 2 & \\
\hline$\sqrt{x}$ & $\mathrm{x}$ & $\sqrt{ }$ & $\sqrt{ }$ & 1 & \\
\hline$x \sqrt{ }$ & $\mathrm{x}$ & $\sqrt{ }$ & $\sqrt{ }$ & 5 & \\
\hline$x \sqrt{ }$ & $\sqrt{ }$ & $\sqrt{ }$ & $\sqrt{ }$ & 2 & \\
\hline$\sqrt{ } \sqrt{ }$ & $\mathrm{x}$ & $\sqrt{ }$ & $\sqrt{ }$ & 1 & \\
\hline $\mathrm{x} x$ & $\mathrm{x}$ & $\mathrm{x}$ & $\mathrm{x}$ & 14 & \\
\hline Rules & rules & $\mathrm{x}$ & $\mathrm{x}$ & $\mathrm{x}$ & 34 \\
\hline X X & $\mathrm{x}$ & rules & $\mathrm{x}$ & 4 & \\
\hline $\mathrm{XX}$ & $\mathrm{x}$ & $\mathrm{x}$ & rules & 3 & \\
\hline $\mathrm{XX}$ & $\mathrm{x}$ & rules & rules & 3 & \\
\hline Total & & & & & 133 \\
\hline
\end{tabular}

Only a few demonstrated the use of more than one method to solve linear equations of various types. As noted, this could be because the linear topics may be perceived to be easier and therefore students did not feel the need to write all they need to know about them when asked about expressing their knowledge of the area. Also, in the preparation sheet students may want to cover the apparently more difficult topics such as quadratics and limits but their work overall did not show significantly different results from linear apart from the conceptual competence in quadratics. The results showed somewhat similar but lower levels of procedural competence on limits and quadratics. Table 11 shows that the students' levels in procedural and logical competencies were similar in both quadratics $(46 \%$, $43 \%)$ and limits $(49 \%, 40 \%)$. The quadratic rule played a major part in quadratic section and as it seemed to be the focus of student work, rather than applications of the same to real life or theoretical examples.

Table 6 shows that around $65 \%(86 / 133)$ of students simply presented the quadratic formula in isolation; that is, not defining the terms in the quadratic formula or relating it in any way spatially to the general form. Only $15 \%(20 / 133)$ of students presented an example applying the formula to calculate the values of $\mathrm{x}$ for which $\mathrm{y}$ was equal to zero. None related this solution to graphs stating-the $\mathrm{x}$ axis intercepts. Moreover, only 9.8\% $(13 / 133)$ of students identified the terms before applying the formula to an example. A low 2.3\% (3/133) of students annotated (identified a, b and c) an example with the steps taken to solve the quadratic.
Around $65 \%$ (87/133) of the students did not present information regarding factorizing being possible a method to solve a quadratic equation (Table 7). A low $14.3 \%$ $(19 / 133)$ of students provided information about expansions types such as $(a+b)^{2}=a^{2}+2 a b+b^{2}$ but the presentation was not typically related to other work. Only $18 \%$ (24/133) of students presented a worked example of how to solve a quadratic equation by factorization.

No students mentioned any of the uses or applications of a completed square form. About 26\% (34/133) of students presented a worked example of completing the squares to solve a quadratic equation (Table 8). Only 6\% (8/133) annotated the worked example to explain the process, whereas the majority of students $(74 \%$ i.e. $99 / 133)$ did not use or even mention the completing of the square as a method of graphing parabolas-finding vertices of a parabola or solving any quadratic equation for $y=f(x)=0$.

Table 9 shows that around 17\% (23/133) of students wrote an example based on the substitution method to determine the limit of a function. Around 39\% (52/133) students used factorization as a method to determine the limit of a function and only $1.5 \%(2 / 133)$ used highest power of $\mathrm{x}$ in the denominator as a method to determine the limit of a function. It was possible that there was some transfer of knowledge to the topic on limits from earlier work on quadratics-factorisation in that student gave a number of factorisation examples but interestingly only $18 \%(24 / 133)$ considered this method when solving a quadratic because such a method when used saves much precious time that would then be available to deal with other problem solving related cognitive processes. 
Table 6. Quadratic formula

\begin{tabular}{|c|c|c|c|c|}
\hline Formula & Terms identified & Example & Annotation & Frequency \\
\hline$\sqrt{x}$ & $\mathrm{x}$ & $\mathrm{x}$ & 86 & \\
\hline$\sqrt{ } \sqrt{ }$ & $\mathrm{x}$ & $\mathrm{x}$ & 4 & \\
\hline$\sqrt{ } x$ & $\sqrt{ }$ & $\mathrm{x}$ & 9 & \\
\hline$\sqrt{ } \sqrt{ }$ & $\sqrt{ }$ & $\mathrm{x}$ & 8 & \\
\hline$\sqrt{ } x$ & $\sqrt{ }$ & $\sqrt{ }$ & 2 & \\
\hline$\sqrt{ } \sqrt{ }$ & $\sqrt{ }$ & $\sqrt{ }$ & 1 & \\
\hline $\mathrm{x} x$ & $\mathrm{x}$ & $\mathrm{x}$ & 23 & \\
\hline Total & & & & 133 \\
\hline
\end{tabular}

Table 7. Quadratic factorising

\begin{tabular}{|c|c|c|c|}
\hline Expansion & Example & Annotation & Frequency \\
\hline$\sqrt{x}$ & $\mathrm{x}$ & 19 & \\
\hline$\sqrt{ } x$ & $\sqrt{ }$ & 3 & \\
\hline$\sqrt{ } \sqrt{ }$ & $\mathrm{x}$ & 2 & \\
\hline$\sqrt{ } \sqrt{ }$ & $\sqrt{ }$ & 0 & \\
\hline $\mathrm{x} x$ & $\mathrm{x}$ & 87 & \\
\hline$x \sqrt{ }$ & $\mathrm{x}$ & 22 & \\
\hline$x \sqrt{ }$ & $\sqrt{ }$ & 0 & \\
\hline Total & & & 133 \\
\hline
\end{tabular}

Table 8. Quadratic completing the squares

\begin{tabular}{llll}
\hline Example & Annotated & Procedural steps & Frequency \\
\hline$\sqrt{ } \mathrm{x}$ & $\sqrt{ }$ & 15 & \\
$\sqrt{\mathrm{x}}$ & $\mathrm{x}$ & 11 & \\
$\sqrt{ } \sqrt{ }$ & $\mathrm{x}$ & 9 & \\
$\mathrm{x} x$ & $\mathrm{x}$ & & 133 \\
Total & & & 99 \\
\hline
\end{tabular}

Table 9. Limit section

\begin{tabular}{lllr}
\hline Method & Example & Annotation & Frequency \\
\hline Substitution & $\sqrt{ }$ & x & 21 \\
$\sqrt{ }$ & $\sqrt{ }$ & 2 & 49 \\
Factorize & $\sqrt{ }$ & $\mathrm{x}$ & \\
$\sqrt{ }$ & $\sqrt{ }$ & 3 & 1 \\
Highest Power & $\sqrt{ }$ & $\mathrm{x}$ & \\
$\sqrt{ }$ & $\sqrt{ }$ & 1 & 56 \\
None & & & 133 \\
Total & & & \\
\hline
\end{tabular}

This evidence may show that students may just be restating the work learned in limits rather than being more creative and relating the method to factorizing in the topic of quadratics. It seems that that procedural and memory based learning approaches may have been the focus for student learning in limits for mostly such factorized examples were noted; rather than any evidence of deeper insights into the connective nature of topics; the relation of limits to hyperbola graphing for example; no students made a connection or link to hyperbolas and asymptotic nature of graphing. There was no evidence of student thinking or linking of ideas regarding approaching values such aswhen
" $x$ gets closer to zero $y$ gets closer to infinity type" understanding of limits. Rather, a simple rule based work was evident in student work on limits. It was similar to quadratics where only a few students delved deeper to consider various ways in quadratics could be understood, applied or solved, the student did not demonstrate an approaching concept or idea; the idea of how very large numbers affect the value of a function was not evident in the work on limits; instead the students appeared to think that limit was "a plugging in of a value"-but this is a lower level understanding of limits. An asymptotic type understanding of limits of functions learned while graphing 
hyperbolas was not connected to or demonstrated and this suggests that the transfer or connections of content knowledge was missing. The lack of connections made across topics helps explain the lower levels in higher order thinking and creativity noted in this study.

Figure 2 shows the distribution of all scores over all competencies attained by students. There are three topics per each score. There is an overall trend downwards towards the higher scores (max 20). Small numbers of students are high (score $>13$ ) in linear and quadratics while there are hardly any above a score of 13 for limits. As expected the quadratics and limits are higher frequency than linear at a low scores of 4 and 5; as expected the linear has more of the higher scores overall yet the limits and quadratics are higher at 7, 11 and 12; this is probably influenced by the relatively higher conceptual scores in quadratics. Most student had low scores in linear, quadratic and limits sections (Fig. 3-5).

\subsection{Summary}

Overall $51 \%$ of students showed procedural competency and $46 \%$ showed conceptual competency (Table 11). The alternate view is more than $49 \%$ of students demonstrated neither procedural nor conceptual competency on their knowledge. Fewer than $32 \%$ of students showed satisfactory logical reasoning in the layout of work such as showing the links between concepts and worked examples or even grouping worked examples showing different methods of solving particular type of problem-linear, quadratic or limit. Fewer than $10 \%$ of students demonstrated a satisfactory level of creativity in their work as well as their presentation of mathematical information regarding a specific topic; linking concepts and relating application to real life or using graphical interpretations to illustrate how the problem and solutions as they related to them was seriously lacking.

If logic was considered as a measure of step by step working of a solution, then around $42 \%$ of the students would have had demonstrated a satisfactory level of logical competence; that is, still lower than the proportion of students who showed procedural competence even when the examples and work the students demonstrated were used to judge the logical nature of presented work. This somewhat higher level of overall competency in logical thinking is not appropriate and certainly not conducive to mathematical learning.
Another view of the overall data is presented in Figure 6, 7 and Table 10, 11, categorizing students as either competent or of low competency. The data show a high number of students in the Low Competence (LC) in both conceptual and procedural categories when compared with competent students (C). More concerning is the fact that many more students are in the low level of logical and creative competencies. This may explain why students fail to undertake higher mathematical studies or courses. The lack of algebra and calculus type knowledge clearly does not allow students later to consider any higher level of general quantitative type courses and only attempt the math courses if they are compulsory. There are concerns regarding the self-preparation levels of students in that students continue not to be too concerned about the university learning in that lecture attendance is now an issue at universities. It seems that studying for passing exams and revising just before exams are key features of time management. Rather than doing more than the minimum required weekly and over the semester for courses, students do leave much revising for the end of the semester. It is then dependent on the university personnel or lecturers to guide and often change the assessment methods and styles to engage students into learning over a semester; that is, the university ends up organising student time management when in fact this should a part of student learning during their university life. Evidence now suggests that many students still continue to do the minimum preparation throughout semester even when the mathematics courses are well recognised to be more abstract and difficult to grasp and learn; math needs consistent and active work throughout the semester. The student preparation and time management for assessment is mostly provided and guided by the university, rather than "gently forcing" student engagement and acquisition of these abilities.

The findings also explain why so many of the students often dislike mathematics at universities. This is mainly because given their basic algebra and calculus skills are at a rather low level. Additionally, the students possess rather low levels of logical and creative competencies when these are critical for higher mathematical studies. In turn, this situation further compounds negative beliefs, students' fear of failure and lowers motivation thus limiting student options to acquire higher science or mathematical knowledge. 


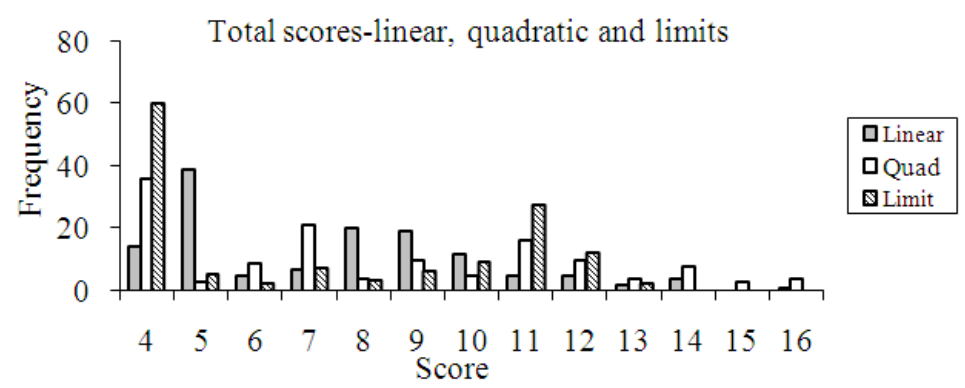

Fig. 2. Frequency distribution of overall performance for each of the three topics

Performance-linear

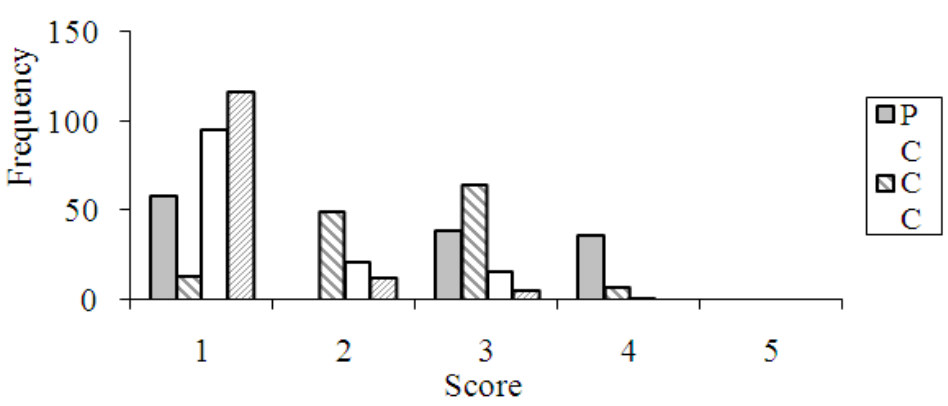

Fig. 3. Performance on linear

Performance-quadratic

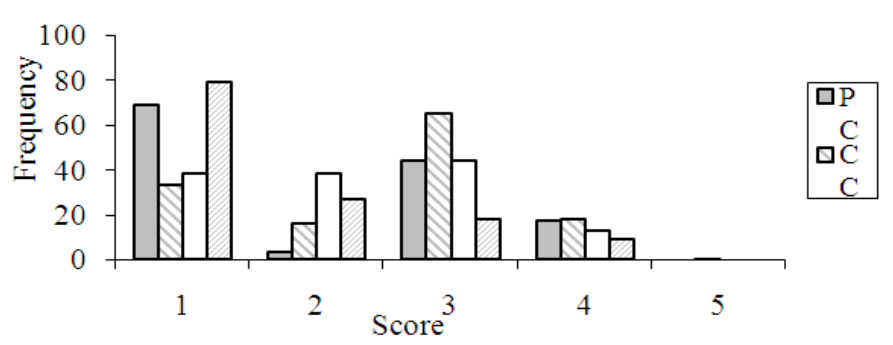

Fig. 4. Performance on quadratic

Performance-limit

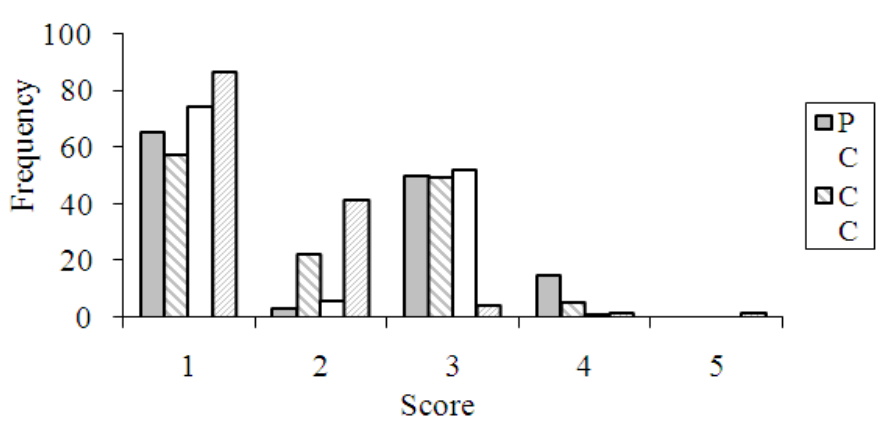

Fig. 5. Performance on limits 
Gurudeo Anand Tularam and Kees Hulsman / Journal of Mathematics and Statistics 9 (3): 219-237, 2013

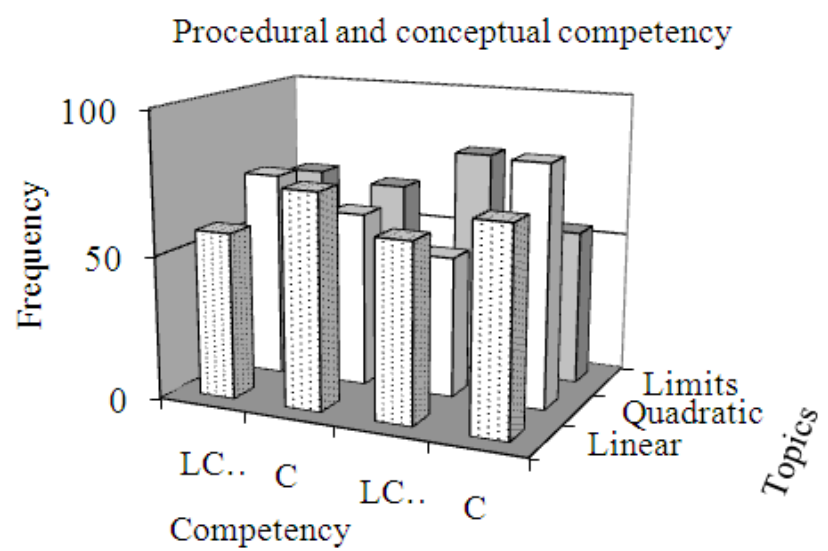

Fig. 6. Level of procedural and conceptual competency across topics

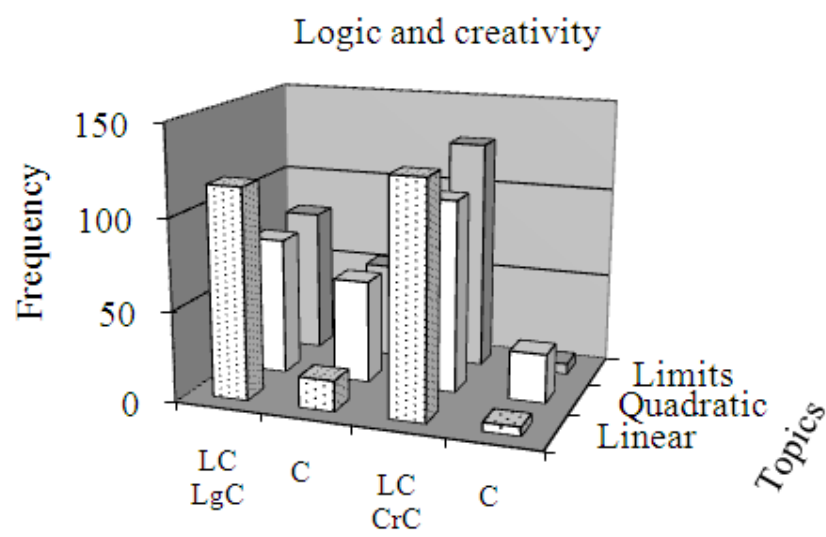

Competency

Fig. 7. Levels of logic and creativity across topics

Table 10. Frequency distribution of competency level - linear, quadratic and limit

\begin{tabular}{|c|c|c|c|c|c|c|c|c|}
\hline \multirow[b]{2}{*}{ Topic } & \multicolumn{2}{|c|}{ Procedural competence } & \multicolumn{2}{|c|}{ Conceptual competence } & \multicolumn{2}{|c|}{ Logical } & \multicolumn{2}{|c|}{ Creativity } \\
\hline & LC & $\mathrm{C}$ & $\mathrm{LC}$ & $\mathrm{C}$ & $\mathrm{LC}$ & $\mathrm{C}$ & $\mathrm{LC}$ & $\mathrm{C}$ \\
\hline Linear & 55.0 & 78.0 & 89.0 & 44.0 & 116.0 & 17.0 & 128.0 & 5.0 \\
\hline Quadratic & 72.0 & 61.0 & 49.0 & 84.0 & 76.0 & 57.0 & 106.0 & 27.0 \\
\hline Limits & 68.0 & 65.0 & 79.0 & 54.0 & 80.0 & 53.0 & 127.0 & 6.0 \\
\hline Mean $(\%)$ & 48.8 & 51.1 & 54.3 & 45.6 & 68.2 & 31.8 & 90.5 & 9.5 \\
\hline
\end{tabular}

Table 11. Overall proportion - competency level versus topic

\begin{tabular}{|c|c|c|c|c|c|c|c|c|}
\hline \multirow[b]{2}{*}{ Procedural } & \multicolumn{2}{|c|}{ Conceptual } & \multicolumn{2}{|c|}{ Logical } & \multicolumn{2}{|c|}{ Creativity } & \multirow[b]{2}{*}{$\mathrm{LC}$} & \multirow[b]{2}{*}{$\mathrm{C}$} \\
\hline & $\mathrm{LC}$ & $\mathrm{C}$ & $\mathrm{LC}$ & $\mathrm{C}$ & $\mathrm{LC}$ & $\mathrm{C}$ & & \\
\hline Linear & 0.41 & 0.59 & 0.67 & 0.33 & 0.87 & 0.13 & 0.96 & 0.04 \\
\hline Quadratic & 0.54 & 0.46 & 0.37 & 0.63 & 0.57 & 0.43 & 0.80 & 0.20 \\
\hline Limit & 0.51 & 0.49 & 0.59 & 0.41 & 0.60 & 0.40 & 0.95 & 0.05 \\
\hline Mean & 0.49 & 0.51 & 0.54 & 0.46 & 0.68 & 0.32 & 0.90 & 0.10 \\
\hline
\end{tabular}




\section{CONCLUSION}

The aim of this study was to understand practical reasons why students after having completed a number of years of secondary schooling in mathematics successfully continue to find mathematics difficult in the environmental sciences where the demands on mathematical and quantitative skills are much less than strict math majors. The overall analysis conducted in this study showed that students did not show significantly developed procedural or conceptual understanding in some basic topics of mathematics. The students' logical and creative competencies were noted to be particularly low for the university level mathematical learning. It is critical to realise higher order thinking skills are important in mathematics learning as these skills can often determine whether students attain higher abstract notions that are prerequisites for continuing with mathematically based courses such as those required for the strict sciences. The lower number of students continuing with mathematics and sciences is a major problem for Australia and these problem therefore need urgent attention.

One of the critical and first requirements in mathematics is the understanding of algebra, linear functions, quadratics and limits and the findings of this study particularly questions the nature of student learning in secondary schools. Not so much that the teachers are to be blamed but the students themselves need much self-examination regarding their priorities for developing learning tools for later life. Also, students need to think more visionary terms such as to help in the building of the nation of Australia, which is on par with the advanced nations of the world in all areas including applications and cutting edge knowledge base. This leads to the heart of the matter whether or not students are seriously engaged in learning mathematics when being taught in Australian classrooms. The class discipline and management may be questioned as to whether these allow students who are well-prepared to engage in serious learning. In all of these, the most important factor appears to be whether the students at that age are themselves mature enough and at the same time prepared for learning abstract mathematics.

The results and findings suggest that prior mathematical knowledge of students influences the development of higher order and more structured mathematical understanding. It is evident that much work has been done on learning and transfer of mathematical knowledge in recent times; yet it is noteworthy that as far back as in 1994, Gates (1994) said "to reach their potential level of transfer they would need to further their mathematical knowledge and understanding, that is, in both depth and clarity" (p. 294). The importance of the nature and conceptual structure of student knowledge base is confirmed in this study. That is, a good body of knowledge is a perquisite for higher learning but the same knowledge should be easily recalled and demonstrated in terms of concepts' depth and clarity in both procedure and application. As noted earlier, results also show why so many of the students dislike mathematics in universities; it is because students' basic algebra concept and skills are at a rather low level. The students showed an inadequate knowledge of limits as used in graphing or when applied in calculus. In addition, the students demonstrated rather low levels of logical and creative competencies that are critical for higher mathematical and science learning. This state of affairs helps promote the development of negative beliefs and students' fear of failure. This in turn limits their growth in gaining further mathematical knowledge and so the cycle continues.

\subsection{Limitations}

There are some limitations in this study as in any other judgement analysis type work there is always subjectivity in appropriately identifying competencies in student work and portioning marks to them. The judgements on logical and creative competencies are usually problematic but in this study judgements were made by an independent marker who has a doctorate but was independent of the teaching team in the mathematical sciences. Although judgements may be problematic and questionable if strict adherence to the set criteria is applied, the difficulties, problems and questions may be minimized. Commonly in the case of quantitative studies, a $95 \%$ confidence interval is presented to demonstrate error in the decisions made. The results should be seen in a similar manner in that the overall marks developed should be viewed as a range rather than a point estimate even when no range can be given. However, if results are subjectively understood as low, very low, satisfactory, high and very high then the categorisation aids the analysis. Even if we allow for some questionable judgements in the analysis the results nevertheless appear to be significant given the rather low levels of competencies achieved by students overall. The findings regarding logical and creative competencies in such a large sample of university students is concerning but they are in line with the current literature. 


\section{REFERENCES}

Bandura, A., 2006. Guide for Constructing Self-Efficacy Scales. In: Self-Efficacy Beliefs of Adolescents (HC). Pajares, F. and T.C. Urban (Eds.), IAP, Greenwich, ISBN-10: 1593113676, pp: 307-337.

Berger, M., 2006. Making mathematical meaning: from preconcepts to pseudoconcepts to concepts. Pythagoras, 63: 14-21. DOI: 10.4102/pythagoras.v0i63.104

De Guzman, M., B.R. Hodgson, A. Robert and V. Villani, 1998. Difficulties in the passage from secondary to tertiary education. Documenta Mathemat.

Gates, L.M., 1994. Transfer of abstract thinking in mathematics. University of Tasmania.

Griese, B., E. Glasmachers, J. Harterich, M. Kallweit and B. Roosken, 2011. Engineering students and their learning of mathematics. Proceedings of the MAVI17 Conference Current State of Research on Mathematical Beliefs XVII, Professional School of Education, RUB, Bochum, pp: 85-96.

Hoyles, C., K. Newman and R. Noss, 2001. Changing patterns of transition from school to university mathematics. Int. J. Math. Educ. Sci. Technol., 32: 829-845. DOI: 10.1080/00207390110067635

Jacobs, M.S., 2006. A description of entry level tertiary students' mathematical achievement: (Towards an analysis of student texts). University of Western Cape.

Kaldo, I., 2011. Identifying dimensions of students' view of mathematics at university level. University of Tallinn.

Kelson, N. and A. Tularam, 1998b. Tutoring with higher mathematics and the use of technology. In Proceedings of the Effective Assessment at University Conference held, Nov, 4-5, Teaching and Educational Development Institute (TEDI), UQ.

Kelson, N.A. and G.A. Tularam, 1998a. Implementation of an integrated, technology-based, discovery mode assessment item involving an incubation period to enhance learning outcomes for engineering maths students. Effective Assessment at University.

Leder, G. and P. Grootenboer, 2005. Editorial. MERJ Math. Educ., 17: 1-8.

Lester, F.K., J. Garofalo and D. Kroll, 1989. SelfConfidence, Interest, Beliefs and Metacognition: Key Influences on Problem-Solving Behavior. In: Affect and Mathematical Problem Solving, McLeod, D.B. and V.M. Adams (Eds.), Springer-Verlag, New York, ISBN-10: 0387969241, pp: 75-88.
Liston, N. and J. O'Donoghue, 2008. The influence of affective variables on students' transition to university mathematics. Topic Study Group 30, ICME.

Liston, N. and J. O'Donoghue, 2010. Factors influencing the transition to university service mathematics: Part 2 a qualitative study. Teach. Math. Applic., 29: 5368. DOI: 10.1093/teamat/hrq005

McLeod, D.B. and V.M. Adams, 1989. Affect and Mathematical Problem Solving. 1st Edn., SpringerVerlag, New York, ISBN-10:0387969241, pp: 268.

McLeod, D.B., 1992. Research on Affect in Mathematics Education: A Reconceptualization. In: Handbook of Research on Mathematics Teaching and Learning, NCTM, Macmillan, New York, ISBN-10: 0029223814, pp: 575-596.

Neubrand, M., 2005. The PISA-study: Challenge and impetus to research in mathematics education. Proceedings of the 29th Conference of the International Group for the Psychology of Mathematics Education, University of Melbourne, Melbourne, pp: 79-82.

Niss, M. and T. Hojgaard, 2011. Competencies in Mathematical Learning: Ideas and Inspiration for the Development of Mathematics Teaching and Learning in Denmark. 1st Edn., Roskilde University, Roskilde.

Piaget, J., 1960. The Psychology of Intelligence. 3rd Edn., Littlefield, Adams, Paterson, pp: 182.

Piaget, J., 1973. Comments on Mathematical Education. Developments in Mathematical Education, Howson, A.G. (Ed.), Cambridge University, Cambridge UK., ISBN-10: 0521098033, pp: 79-87.

Rach, S. and A. Heinze, 2011. Studying Mathematics at the University: The Influence of Learning Strategies. Proceedings of the 35th Conference of the International Group for the Psychology of Mathematics Education, (PME' 11), PME, Ankara, pp: 9-16.

Schoenfeld, A.H., 1985. Mathematical Problem Solving. 3rd Edn., Academic Press, Orlando, ISBN-10: 0126288704, pp: 409.

Sfard, A., 1991. On the dual nature of mathematical conceptions: Reflections on processes and objects as different sides of the same coin. Educ. Stud. Math., 22: 1-36. DOI: 10.1007/BF00302715

Sfard, A., 2000. Symbolizing Mathematical Reality Into Being-Or How Mathematical Discourse and Mathematical Objects Create Each Other. In: Symbolizing and Communicating in Mathematics Classrooms: Perspectives on Discourse, Tools and Instructional Design, Cobb, P., E. Yackel and K. McClain (Eds.), Lawrence Erlbaum Associates, Mahwah, NJ., ISBN-10: 0805829768, pp: 37-98. 
Skaalvik, E.M. and S. Skaalvik, 2009. Self-concept and self-efficacy in mathematics: Relation with mathematics motivation and achievement. J. Educ. Res., 3: 255-278.

Tall, D., 2004. Thinking through three worlds of Mathematics. University of Warwick CV4 7AL, UK.

Tularam, G.A and S. Amri, 2011. Tertiary mathematics learning and performance in first year mathematics in the environmental sciences: a case of student preparedness for learning mathematics. Proceedings of Volcanic Delta, the 8th Southern Hemisphere Conference on Teaching and Learning Undergraduate Mathematics and Statistics, (UMS' 11), University of Canterbury and University of Auckland, Rotorua, New Zealand.

Tularam, G.A., 1997a. The role of algebraic knowledge, higher-order thinking and affective factors on students' performance on novel algebraic wordproblem solving. PhD. Thesis, Queensland University of Technology.
Tularam, G.A., 1997b. The Role of higher order thinking: metacognition and critical thinking in algebraic word problem solving. New Zealand Auckland Institute of Technology, Auckland, NZ.

Tularam, G.A., 2013a. Preparedness of students in first year mathematics: Importance of placing the focus and responsibility of learning on students. Int. J. Educ., 3: 24-33.

Tularam, G.A., 2013b. Mathematics in finance and economics: Importance of teaching higher order mathematical thinking skills in finance. E-J. Bus. Scholarship $\quad$ Educ., $\quad$ 7: 43-73. www.ejbest.org/upload/eJBEST_Tularam_7(1)_2013.pdf

Turner, R., 2010. Exploring mathematical competencies. Australian Council for Educational Research.

Zimmerman, B., A. Bandura and M. Martinez-Pons, 1992. Self-motivation for academic attainment: the role of self-efficacy beliefs and personal goal setting. Am. Educ. Res. J., 29: 663-676. DOI: $10.3102 / 00028312029003663$ 